\title{
Atypical Presentation of Synovial Osteochondromatosis At the Subtalar Joint Mimicking A Fracture Following Trauma: A Case Report
}

\author{
Azammuddin A, Tan JA, Othman MS, Hanif KAA, Halim MAHA and Leong JF* \\ Department of Orthopaedics, Tuanku Jaafar Hospital, Malaysia
}

Received: 漹: December 10, 2018; Published: 制: January 10, 2019

*Corresponding author: Juzaily Fekry Leong, Department of Orthopaedic and Traumatology, Malaysia

\begin{abstract}
Synovial osteo chondromatosis (SOC) are benign tumors arising from metaplastic synovial tissue of joints, bursae or tendon sheath. These tumors are most commonly found in the knee joint and rarely presents in the foot and ankle region. We report a case of a middle age gentleman with primary SOC and was misdiagnosed as an acute neck of talus fracture following trauma. He presented with pain one week after a fall and examination revealed a $4 \times 4 \mathrm{~cm}$ bony hard swelling over the anterolateral aspect of the right ankle joint. Radiograph showed a possible neck of talus fracture but Computer Tomographic (CT) scan revealed no fracture but bony mass within the sinus tarsi and extending to the lateral aspect of the ankle joint. Excision biopsy confirmed SOC and patient recovered fully without any pain and no sign of recurrence after 1-year follow-up. This case highlights the rarity of SOC in the foot and ankle region, which mimicked a fracture of the neck of talus.
\end{abstract}

Keywords: Chondromatosis; Subtalar joint; Synovial

Abbreviations: SOC: Synovial Osteo Chondromatosis; MRI: Magnetic Resonance Imaging; HPE: Histopathology Examination

\section{Introduction}

Synovial osteo chondromatosis (SOC) are benign tumors arising from synovial tissue of joints, bursae or tendon sheath. These synovial tissues undergo metaplasia to form cartilaginous or osteocartilaginous bodies which may break off from the synovial surface, causing pain or mechanical blockage to the joint [1]. Involvement is usually monoarticular, with the large joints being most frequently affected. The knee joint is involved in 60 to $70 \%$ of cases; the shoulder, elbow, and hip are the next most frequently involved joint. It rarely involves the joints of the foot and ankle region [2]. Here we report an atypical presentation of primary SOC of the right subtalar joint in a middle age gentleman, who presented with pain of the right ankle and was misdiagnosed as a right talus fracture, after a traumatic fall in his workplace.

\section{Case Report}

A 40-year-old male was referred to our Orthopedic Department with a history of trivial fall one week ago in his workplace and was diagnosed as a right neck of talus fracture. It is associated with pain and limited range motion of the affected ankle especially on eversion and inversion of ankle. He denied any pain or swelling over the ankle region prior to the above injury. On examination, there is a localized swelling just anterior to the lateral malleolus. On palpation it was tender and firm in consistency. The pain was aggravated with passive inversion and eversion of the subtalar joint. The ankle was otherwise stable. All bloods investigations were normal. Radiographs of the right ankle showed a large calcified mass that contained multiple radiopaque bodies, lateral to the subtalar joint. From the lateral view, there appeared to be a suspicious fracture line traversing the neck of talus (Figure 1). As we were unable to rule out a fracture, we proceeded with a CT scan of the right ankle that reported no obvious fracture but revealed a large bony mass measuring $5 \times 4 \times 4 \mathrm{~cm}$ within the sinus tarsi and extending to the lateral aspect of the ankle joint (Figure 2).

In view of the benign presentation of the tumor an excision biopsy was performed. The surgery was done through anterolateral approach to the talus, exposing the whitish bony hard mass that was sitting in the region of the sinus tarsi. Intraoperative findings showed a solitary whitish bony tumor measuring about $5 \times 4 \times 4 \mathrm{~cm}$ in size (Figure 3a), which was encased by hypertrophied synovium. The disease was noted to have eroded the adjacent plantar surface 
of the talar neck. The tumor was removed as a whole and sent for histopathology examination (HPE). The section showed few chondorocytes arranged in lobules within the synovial which was consistent with synovial chondromatosis. No nuclear atypia was seen, ruling out malignancy (Figure 3b).

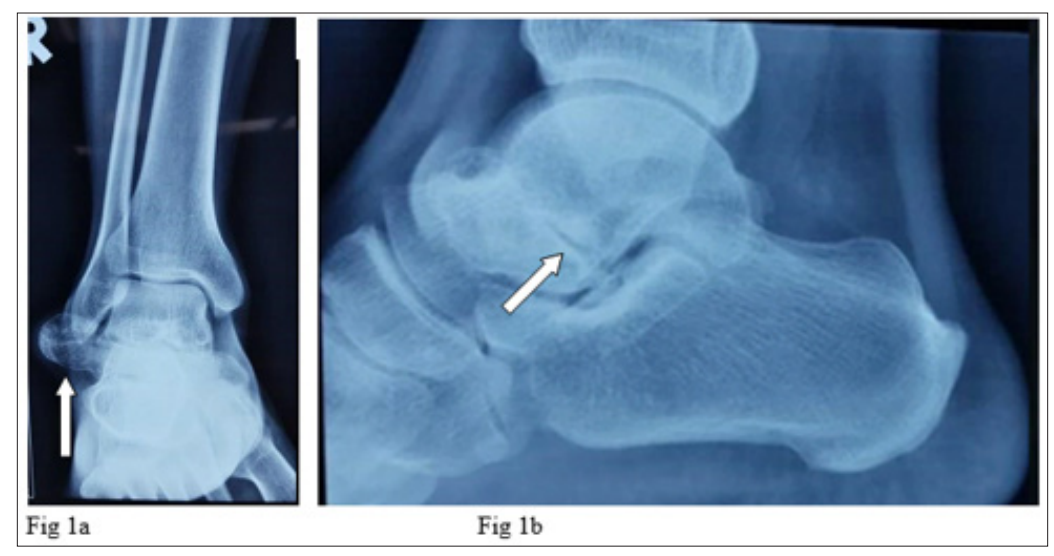

Figure 1: a) AP view of the right ankle showing a calcific mass (arrow) that appears to be in continuity with the subtalar joint.

b) Lateral view of the right ankle showing multi-lobulated calcified mass overlapping the talus with a mistaken fracture line at the neck of talus (arrow).

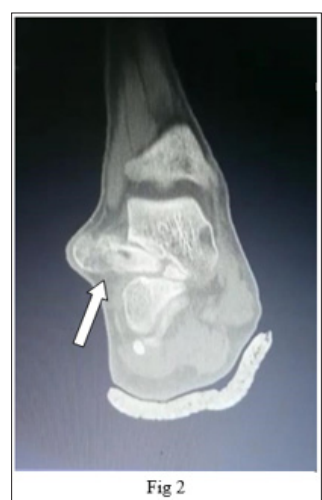

Figure 2: Mid-coronal view of the CT scan showing a bony mass (arrow) arising from the sinus tarsi of the right ankle joint, extending laterally.

\section{Figure 3:}

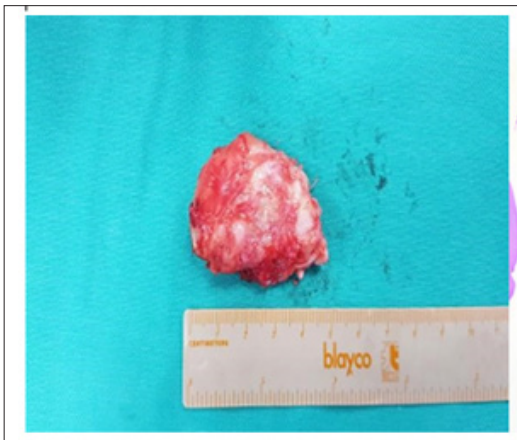

Fig 3a

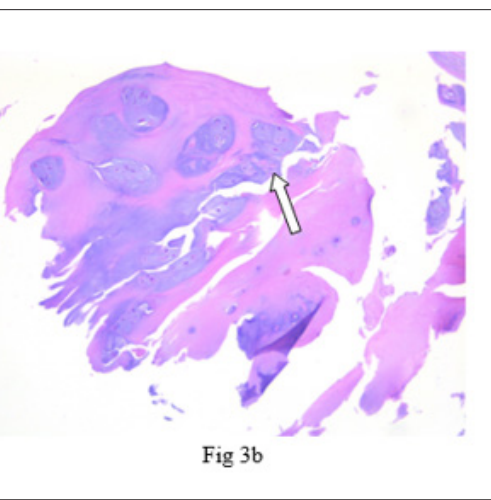

a) Gross specimen of the glossy white osteocartilaginous tumor which was encased by hypertrophied synovium.

b) Section from tissue showed clusters of chondrocytes (arrow) arranged in lobules consistent with diagnosis of SOC, without cellular atypia, ruling out malignancy. 
Post operatively the patient's ankle was immobilized with a below knee backslab for 2 weeks for pain management. After 2 weeks, he was allowed full weight bearing and referred to the physiotherapist for interferential and isometric therapy to achieve full range of movement and functional outcome of the affected ankle [3]. Patient was followed up for 1 year post-operatively and was ambulating normally without pain. There were also no clinical or radiographic evidence of recurrence.

\section{Discussion}

The exact prevalence of SOC is unknown, but the disorder is rare worldwide. Occurrence are more common among males age between 20-40 years, and only a few case reports have described the condition occurring in children [4]. It commonly occurs in synovial joints including the knee, hip and shoulder. However, it is rarely seen in the foot and ankle region [2]. SOC may be divided into primary and secondary forms. Primary SOC differs from its secondary counterpart as it occurs in an apparent normal joint whereas secondary SOC develops in patients with pre-existing arthritis [5]. The pathogenesis of SOC can be divided into three stages. In stage one, there is only active synovial disease without presence of loose bodies. Stage two disease would include formation of loose bodies on top of active synovial disease and stage three would only have loose bodies without evidence of synovial disease. In our patient, the SOC was in stage two as evident by the bony tumor being encased by hypertrophied synovium after excision biopsy.

Patients usually present with a palpable nodule, mono-articular pain, swelling, stiffness with or without mechanical symptoms of the joint involved. On examination of the joint, there may be effusion, non-tender palpable mass with reduction of the range of motion. The blood investigations are normal and plain radiographs show large nodules with stippled or ring like calcified opacities. Secondary widening of the joints space may also be noted. CT scan is useful to detect calcified intra-articular loose bodies, bony erosions and the real extent of the lesion, which are difficult to assess using a plain radiograph. In cases like the above, a CT scan would also be useful to exclude the diagnosis of a fracture. Magnetic resonance imaging (MRI) is useful to evaluate the status of the ligaments and adjacent articular cartilage especially when the disease is at its early stages. Tissue biopsy remains the gold standard of diagnosis and will provide useful information to exclude other differential diagnosis especially malignant conditions [4].
Treatment of patients with SOC are tailored according to their presenting symptoms. Asymptomatic patients do not require surgical management and mere observation with regular follow-ups would be sufficient. In patients presenting with pain, or mechanical symptoms, surgical management may be offered. The traditional surgical approach is an open arthrotomy of the joint with removal of all loose bodies with extensive synovectomy. Recent advancements have enabled these loose bodies to be removed arthroscopically [6]. In the present case, open surgery was performed due to its large size and tightness of the subtalar joint.

Patients with SOC must also be counselled regarding the risk of recurrence. The recurrence risk after surgical removal are variable ranging from $3.2 \%$ to $22.3 \%$ [7]. In the above patient, there was no evidence of recurrence in six months post-operatively, but longer follow-up must be done in case of future recurrence.

\section{Conclusion}

Primary SOC even though rare in the foot and ankle region, must be taken into consideration in patients presenting with slow growing benign bony mass over the mentioned joint. Surgical excision offers good functional outcome with low rates of recurrence.

\section{References}

1. Kirchhoff C, Buhmann S, Braunstein V, Weiler V, Mutschler W, et al. (2008) Synovial chondromatosis of the long biceps tendon sheath in a child: a case report and review of the literature. J Shoulder Elbow Surg 17(3): e6-e10.

2. Kerimoglu S, Aynaci O, Saraçoglu M, Cobanoglu U (2008) Synovial chondromatosis of the subtalar joint: a case report and review of the literature. J Am Podiatr Med Assoc 98(4): 318-321.

3. Pallavi B, Vaishali J, Devi TP (2017) Effect of circuit training in osteoarthritis of the knee. Asian J Pharm Clin Res 10: 333-335.

4. Wodajo F, Gannon F, Murphey M (2010) Visual Guide to Musculoskeletal Tumors: A Clinical - Radiologic - Histologic Approach. Saunders.

5. Lin YC, Goldsmith JD, Gebhardt MG, Wu JS (2014) Bursal synovial chondromatosis formation following osteochondroma resection. Skeletal Radiol 43(7): 997-1000.

6. Doral MN, Uzumcugil A, Bozkurt M, Atay OA, Cil A, et al. (2007) Arthroscopic treatment of synovial chondromatosis of the ankle. J Foot Ankle Surg 46: 192-195.

7. Davis R, Hamilton A, Biggart JD (1998) Primary synovial chondromatosis: A clinicopathologic review and assessment of malignant potential. Human Pathology 29(7): 683-688.
ISSN: 2574-1241

DOI: 10.26717/BJSTR.2019.13.002341

Juzaily Fekry Leong. Biomed J Sci \& Tech Res

This work is licensed under Creative Commons Attribution 4.0 License

Submission Link: https://biomedres.us/submit-manuscript.php

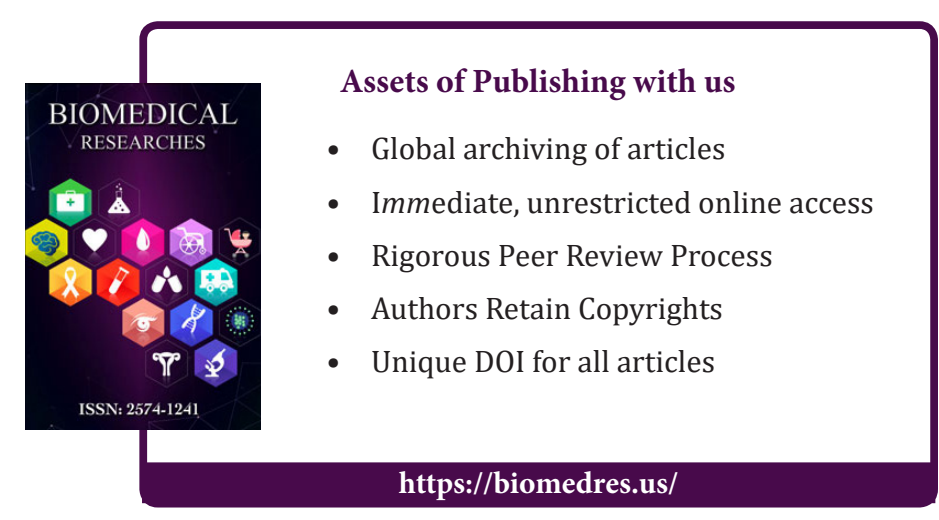

Cite this article: Azammuddin A, Tan JA, Othman MS, Hanif KAA, Halim MAHA, Leong JF. Atypical Presentation of Synovial Osteochondromatosis At the Subtalar Joint Mimicking A Fracture Following Trauma: A Case Report. Biomed J Sci \& Tech Res 13(1)-2019. BJSTR. MS.ID.002341. DOI: 10.26717/ BJSTR.2019.13.002341. 